\title{
La práctica artística del escultor contemporáneo y los materiales
}

\author{
M. ${ }^{a}$ Teresa González Vicario*
}

\begin{abstract}
RESUMEN ABSTRACT
La escultura ha experimentado en el siglo $x x$, al igual que la pintura, determinados cambios que han alterado, y a la vez revitalizado, la práctica artística del escultor. El lenguaje de las vanguardias se tradujo en la ruptura con los postulados artísticos anteriores $y$, consecuentemente, en la aparición de una estética nueva, a lo que también se sumó el progreso científico y tecnológico, con la aparición de materiales y técnicas nuevos que introdujeron cambios radicales. Acercarse a algunos de dichos cambios, que han modificado la práctica artística del escultor. constituye el propósito de este artículo.

Sculpture, as painting, has experienced in the Twentieth Century a series of changes that have altered and revitalized the artistic praxis of the sculptor. The language of modernism produced a rupture with old norms and the apparition of a new esthetic. To this we may add the evolution of science and tecnology, which introduced new tecniques and materials in sculpture and produced some radical changes. The purpose of this article is to present some of these changes that have altered the work of the sculptor.
\end{abstract}

\footnotetext{
* Departamento de Historia del Arte. UNED.
} 
Durante siglos, la forma escultórica ha sido una manifestación de la actividad artística del hombre y también un testimonio de su lucha con la materia, que siempre le ha exigido la utilización de una técnica determinada. La belleza y la armonía de la escultura griega fueron reconocidas por Occidente como el modelo a seguir, por lo que las representaciones antropomórficas se convirtieron, siguiendo aquellos modelos clásicos, en el eje de nuestra escultura, que tradicionalmente ha empleado la piedra, el mármol, el bronce o la madera. Pero junto a la elección del material, la actividad artística le exige también al escultor el empleo de la técnica adecuada: la talla, el modelado y el vaciado en metal, métodos también tradicionales en el proceso escultórico.

Con el siglo $x x$, sin embargo, hizo su aparición un nuevo lenguaje -el de las vanguardias - que rompía con los postulados artísticos anteriores y provocó la aparición de una estética nueva, no enfrentada a la fealdad, lo cual supuso un cambio sustancial en la práctica de la escultura. Además, se ha producido una clara voluntad de ruptura que conduce también a la eliminación de las fronteras entre las artes, por lo que frecuentemente se hace referencia a la "esculto-pintura" " o a la "esculto-arquitectura", términos muy elocuentes y significativos de una realidad artística nueva que ha prescindido del sistema de representación renacentista. No obstante, y como señala Valeriano Bozal, «la crisis del lenguaje plástico tradicional no se debe a un intento de huir de la realidad. Bien al contrario, es el afán de representarla mejor el que la produce»?2.

Consecuentemente, la práctica artística del escultor se ha visto modificada por la audaz e innovadora sucesión de concepciones del siglo xx, y en tal sentido, movimientos como el Cubismo, el Futurismo, el Constructivismo, el Dadaísmo y el Surrealismo resultan esenciales para la comprensión del origen y desarrollo posterior de las realizaciones artísticas de este siglo. El Cubismo, con su valoración del arte primitivo y de la obra de Cezanne, revisó el concepto tradicional del volumen en función del juego de la geometría de las formas, del vacío y de la desarticulación de lo sólido en la obra escultórica.

En su incesante búsqueda artística, Pablo Picasso (1881-1973) originó un universo formal con el que rompió los valores escultóricos tradiciona-

Dicho término, inventado por Alexandre Rodchenko, se refiere a una modalidad plástica que en España ha sido y es cultivada por artistas diferentes, tales como Manuel Millares, Manuel Rivera, Salvador Soria y Lucio Muñoz, entre otros. Véase: AREAN, C.: Balance del arte joven en España. Madrid, Publicaciones Españolas, 1971, págs. 53 y 68-74

BozAl, V.: Los primeros diez años. 1900-1910, los origenes del arte contemporáneo. Madrid, Visor, 1991, pág. 25. 
les al utilizar unos materiales y unas técnicas no convencionales. Sin embargo, ¿podemos considerar esculturas a la Guitarra (fig. 1) o a la Cabeza de toro (fig. 2)? No, en su sentido tradicional, puesto que ni por la técnica ni por el material empleado, ni por su lenguaje formal, se ajustan al concepto que convencionalmente se ha tenido de la escultura. Por el procedimiento del ensamblaje. Picasso acopló en un todo materiales heterogéneos, objetos encontrados y no creados con una finalidad artística, pero a los que dotó de un significado nuevo. De igual forma, también realizó obras construidas en metal, con lo que se modificó el concepto que tradicionalmente se tenía de la escultura. Frente a la talla y el modelado, un método nuevo, el de la construcción, introdujo un cambio radical al utilizarse materiales y técnicas procedentes del mundo industrial. Surge así una actitud nueva y un oficio tecnológico del escultor propio del siglo $x x$. Según Margit Rowell, "los ensamblajes de Picasso, en los que las delgadas formas planas e irregulares, ajustadas de manera precaria y a veces cubiertas de pintura o de un dibujo, circunscribian y delimitaban unos vacios en el espacio, estos ensamblajes destruyen en sus fundamentos la idea de la escultura como volumen o masa situada en una relación determinada con su espacio circundante, exigiendo el uso de ciertos materiales y técnicas y dedicada a unos temas determinados. Estos frágiles objetos, sacados de las manos de Picasso, han hecho tabla rasa de toda la historia de la escultura occidental y presiden el nacimiento de la época moderna” ${ }^{3}$.

Cuando Vladimir Tatlin (1885-1953) visitó París en 1912 y conoció algunas de las construcciones de Picasso, al regresar a Moscú realizó bajo su influencia sus Cuadros-relieves, en los que con distintos materiales vidrio, madera, metal, cartón, goma y brea-construyó unas obras basadas en un planteamiento formal abstracto. Otras construcciones suyas son los Contrarrelieves (fig. 3), obras sin pie, pensadas para ser colgadas en los ángulos de las habitaciones. Más relacionado con la arquitectura que con la escultura, su Monumento a la III Internacional, realizado entre 1919 y 1920 , obedece, sin embargo, a una concepción escultórica, ligada a la tecnología moderna, que rompía con el concepto de monumento tradicional, originando otra modalidad revolucionarić, dinámica y con un claro objetivo propagandístico.

Por otro lado, y a pesar de la postura nihilista y destructora del Dadaísmo, que defendía el absurdo y el anti-arte, incluso la negación misma del

Catálogo de la exposición Ou'est-ce que la sculpture moderne? Paris, Centre Georges Pompidou, 1986, pág. 27. 


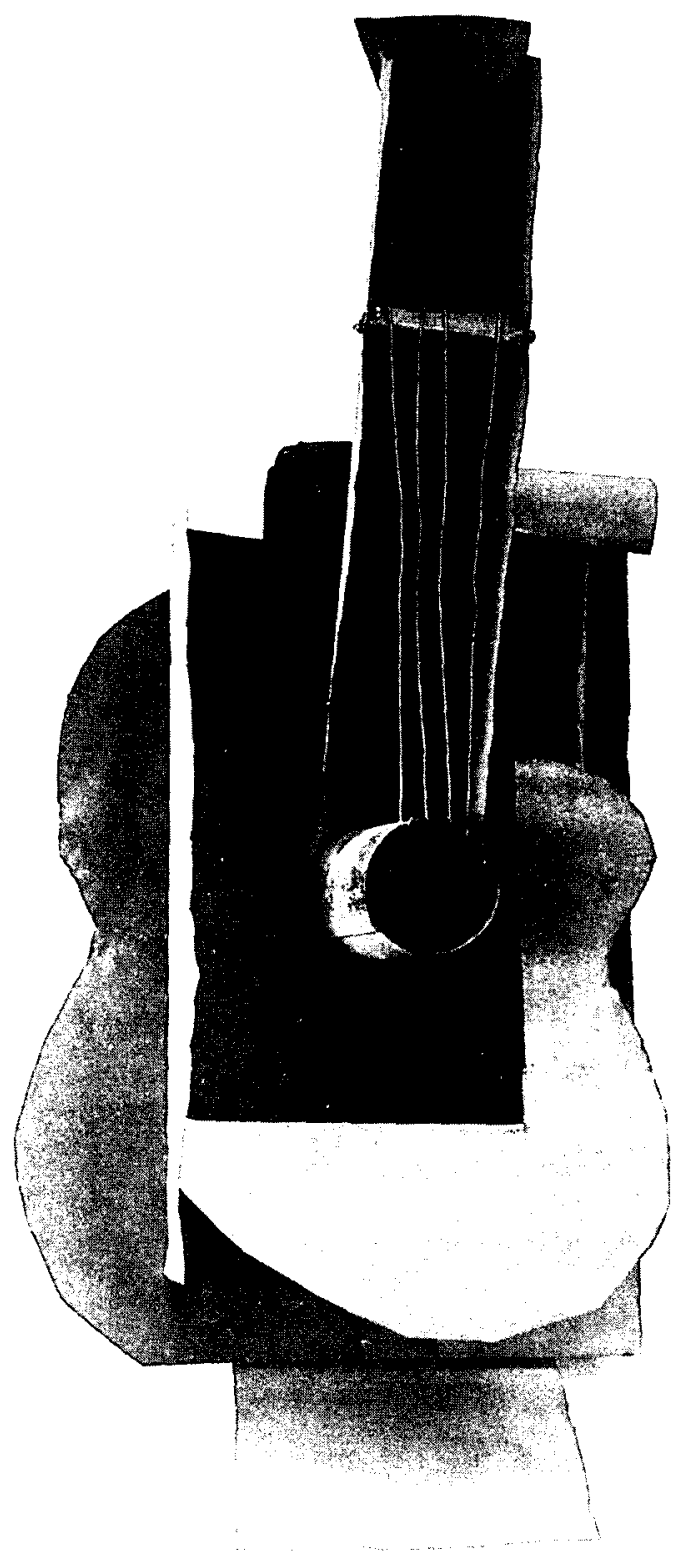

Fig. 1. Pablo Picasso: La guitarra. $77,5 \times 35 \times 19.3 \mathrm{~cm} .1912$. 


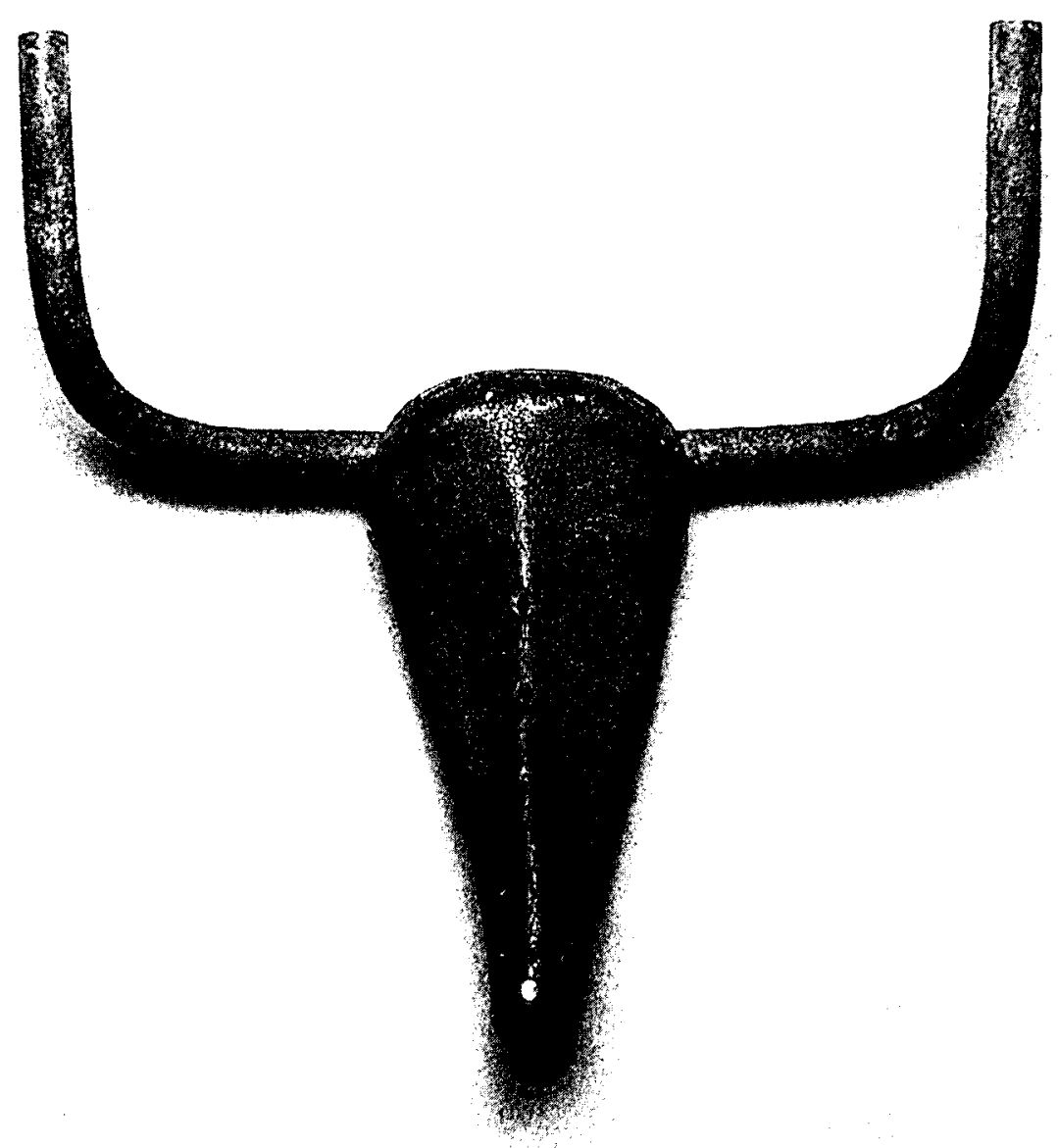

Fig. 2. Pablo Picasso: Cabeza de toro, $33.5 \times 43.5 \times 19 \mathrm{~cm} .1942$.

Arte. paradójicamente este movimiento ha aportado determinadas realizaciones que son de referencia obligada para comprender tendencias que surgirían con posterioridad. Empleó materiales y técnicas nuevos, utilizándose el "collage", el montaje, el ensamblaje e incluso la instaiación, y se sirvió de la poesia fonética, de la tipografía y de la fotografia como procedimientos para expresar su radicalizada postura, en la que. consecuentemente. no había cabida para la tradicional división entre arquitectura, escultura y pintura. 


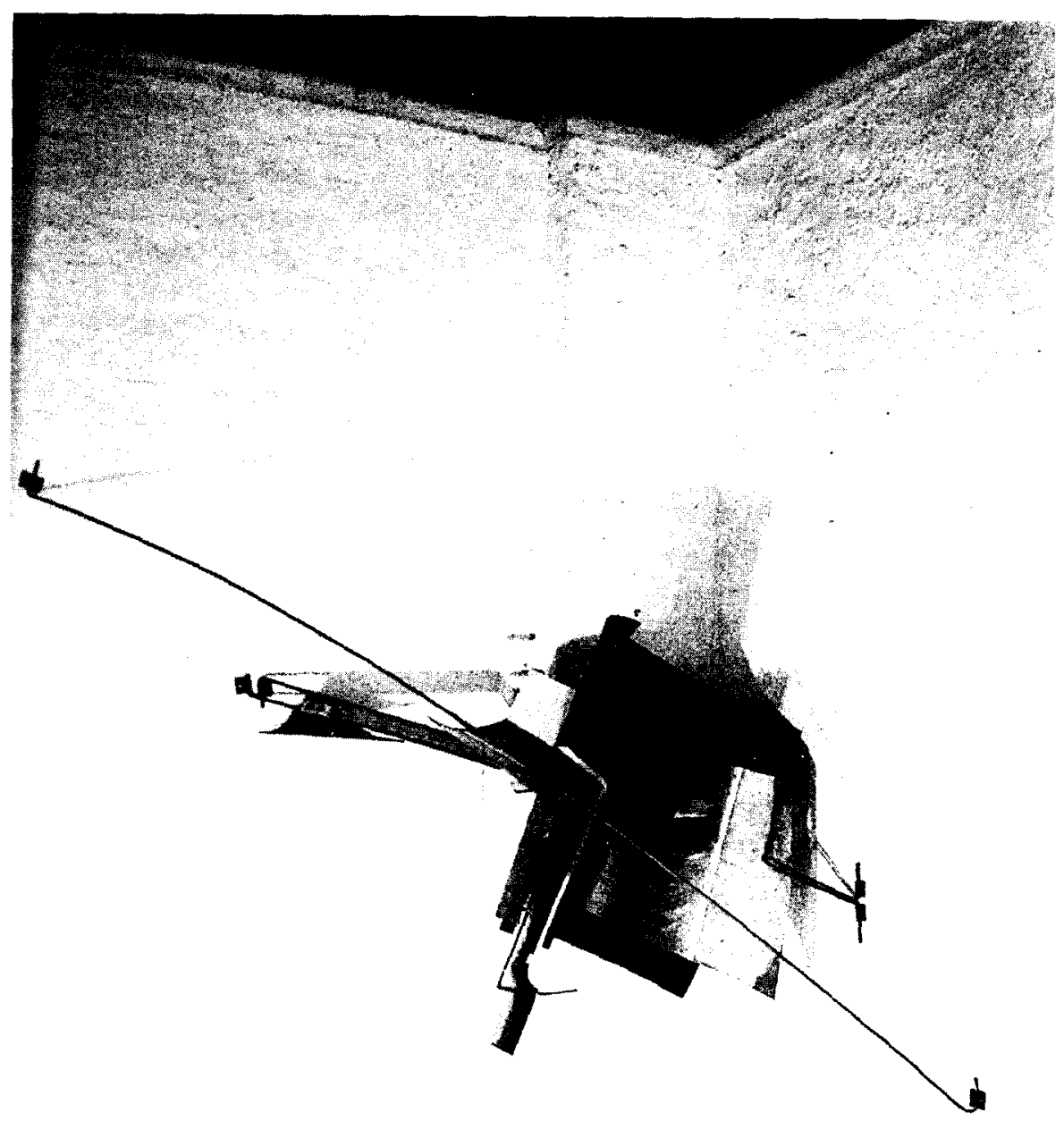

Fig. 3. Vladimir Tatlin: Contrarrelieve, $78,7 \times 152,4 \times 76 \mathrm{~cm} .1915$.

Los "ready-made» de Marcel Duchamp (1887-1968), a los que definió como "objeto usual elevado a la dignidad de objeto artístico por la simple elección del artista", suponían la descontextualización de los objetos que forman parte de lo cotidiano, es decir, aislarios de lo que es su en- 
torno habitual, aunque sin buscar una finalidad estética, para presentarlos ante un público que no encuentra en ellos los valores que encerraba lo que tradicionalmente se había venido considerando como obra de arte; y es precisamente ese afán por desvalorizar el Arte lo que se pone de manifiesto en una rueda de bicicleta (fig. 4), un botellero, un perchero, un urinario, un peine o una pala de nieve, entre otros "ready-made" de Duchamp.

Por su parte, los "Merz" de Kurt Schwitters (1887-1948) - "collages" y ensamblajes a los que a partir de 1919 bautizó con aquella denominación - reunían una variedad de materiales de desecho, de desperdicios, que ha llevado a José Pierre a considerarle un «arqueólogo del presente [cuyas] miradas se dirigieron instintivamente a lo más frágil y despreciado: billetes de autobús, etiquetas, envoltorios de latas de conserva, fragmentos de prospectos, viejas misivas, etc. Lo que le atraía irremediablemente en esos humildes testimonios de la modernidad eran sus colores marchitos, gastados, inciertos y como huidizos" ${ }^{4}$. Estas realizaciones llevaron a Schwitters a los "Merzbau», obras en tres dimensiones, construidas con objetos que iba recogiendo de la calle y que terminaron por ocupar dos pisos de su casa de Hannover.

La práctica de la técnica del "collage" y del "ready-made" ha supuesto, por lo tanto, el punto de partida, el origen, de lo que se ha dado en llamar el "arte del objeto", y del que son deudoras posteriores manifestaciones artísticas que aparecieron a partir de la década de los sesenta. Todos estos movimientos implican la ruptura del orden establecido por los modelos clásicos, que habian sido perpetuados en Occidente por el sistema de representación renacentista y, por consiguiente, un cambio radical en los usos, formas y técnicas de la profesión de escultor. Sin embargo, la escultura, como es sabido, no fue entre las artes la que originó esta radical transformación, ya que desde el principio la pintura acaparó el protagonismo de tales cambios. No obstante, "después de 1945 - como indica Pierre Cabanne - la escultura cree haber conquistado por fin su autonomia, pero su confusión con la pintura y su identificación con el objeto, así como su integración en la arquitectura, van a provocar ambigüedades y mutaciones que acrecentarán el uso de nuevos materiales, el más revolucionario de los cuales, tras las conquistas del cinetismo y el arte óptico, ha sido el

4 PIEARt. J.: El Futurismo y el Dadaismo. Madrid, Aguilar, 1968, pág. 95 


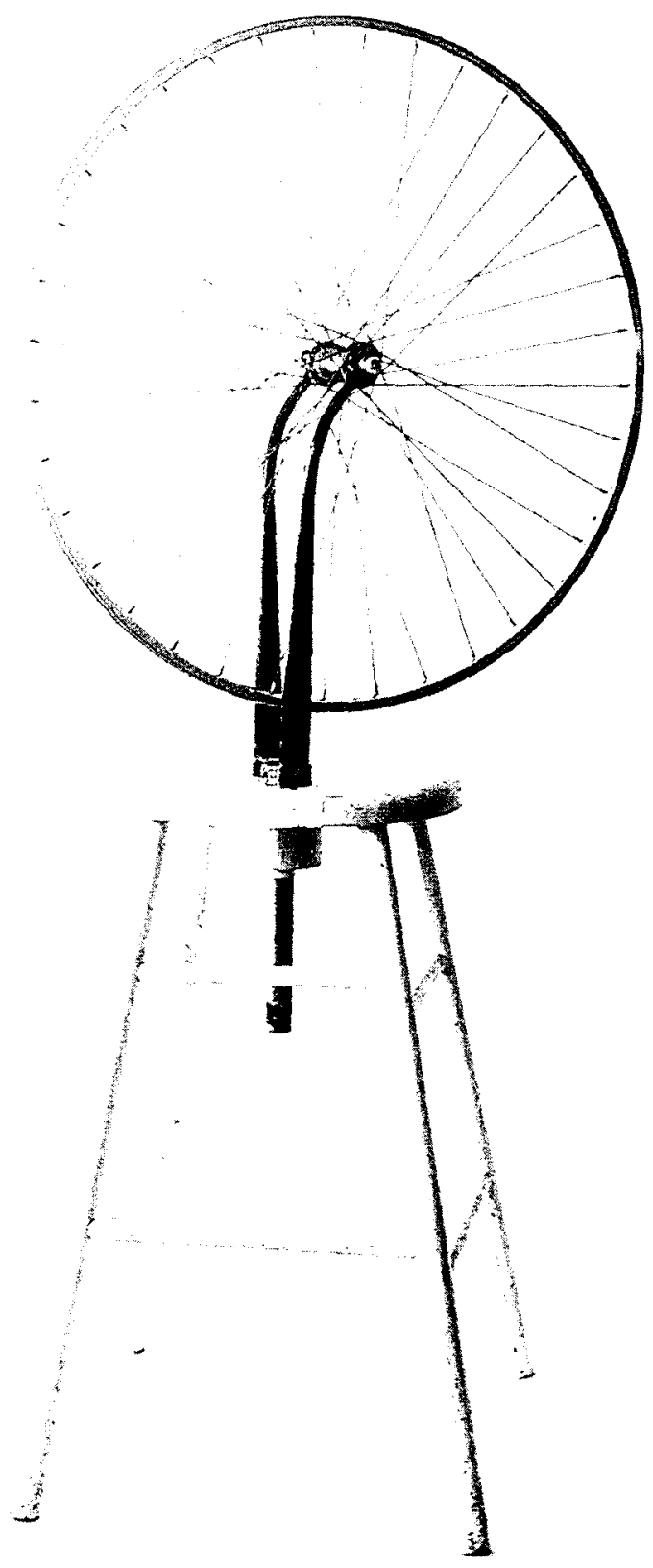

Fig. 4. Marcel Duchamp: Rueda de bicicleta, $125 \mathrm{~cm}, 1913$. 
láser» ${ }^{5}$. Esta ambigüedad que acompaña en la actualidad al concepto de lo escultórico, lleva también a preguntarse si determinadas manifestaciones, tales como el arte conceptual, el «land art», las instalaciones y "performances" pertenecen al campo de la escultura. Al menos, el proceso de ejecución ha introducido cambios radicales en el oficio de los escultores.

La aparición de materiales y técnicas nuevos ${ }^{6}$ ha alterado la práctica artística del escultor contemporáneo. "El artista - señala Pierre Cabanne- abandona su taller y sus herramientas tradicionales para echar mano de la dinamita, el bulldozer y la piedra o «tallar» un prado con un tractor»?

Sin embargo, esta ruptura con respecto al pasado artistico no implica el abandono total de las anteriores prácticas del escultor, puesto que en la actualidad también se siguen empleando los materiales y las técnicas tradicionales, e incluso estas últimas pueden ser aplicadas a los nuevos materiales, no resultando extraño referirse a la "fundición en cemento" ${ }^{8}$.

A pesar de que la obra de Henry Moore (1898-1986) está muy ligada a los materiales y técnicas tradicionales, sin embargo, no despreció en determinadas esculturas la posibilidad de expresarse artísticamente con una materia no convencional. En Mujer reclinada (fig. 5) utilizó el vaciado en

Cabannt, P.: El arte del sialo xx. Barcelona, Poligrafa, 1983, pág. 218.

Sobre los materiales y técnicas nuevos, véase entre otros: CleHin, Ph.: La sculpture, toutes les techniques. Paris, Dessain el Tolra, 1988; MARTINF $Z$ DEL RIO, L. J.: Técnicas industriales de soldadura adaptadas a los procesos de la escultura en metal. Madrid, Universidad Complutense. 1989; Midgl.fy, B. (coord.): Guia completa de escultura, modelado v cerámica. Técnicas y materiales. Madrid. Hermann Blume, 1982; Rosier, P.: La sculpture: Méthodes et matériaux nouveaux. Paris. Dessain et Tolra, 1990: Ruvtl. J.: Técnica de la escultura. México. Fondo de Cultura Económica, 1986

Cabanne, P.: Op. cit., pág. 230.

Este material, de reciente aparición desde el punto de vista escultórico, resulta más barato que la piedra, y tras recibir un tratamiento adecuado, en el que se admiten toda clase de pátinas $e$ incluso variadas coloraciones. se logran obras con auténticas calidades petreas. Para ello se emplean cementos especiales, que pueden ser blancos, gr ses o negros, a los que se añaden pigmentos minerales, para no estropear la naturaleza del cemento, el agua y el árido. casi siempre piedra molida de distinto tamaño - de granulacion fina para las obras que requieren mayor detaHe, y más gruesa para las que son monumentales-- y color. Todo ello contribuye a dar una determinada tonalidad a la escultura, admitiéndose diversas combinaciones, tales como cemento blanco y un árido de mármol blanco, o también cemento negro con piedra de basalto negra molida, e incluso otras mezclas más atrevidas a base de cemento negro y mármoles verdes, etc. El fraguado se hace en moldes que pueden ser de madera o escayola debidamente tratada y, en ocasiones, las huellas del encofrado son motivos aprovechados por el escultor con una finalidad artistica. Junto al encofrado o vaciado, el hormigón admite también la aplicación de otras técnicas. tales como la pulimentación y la talla. 


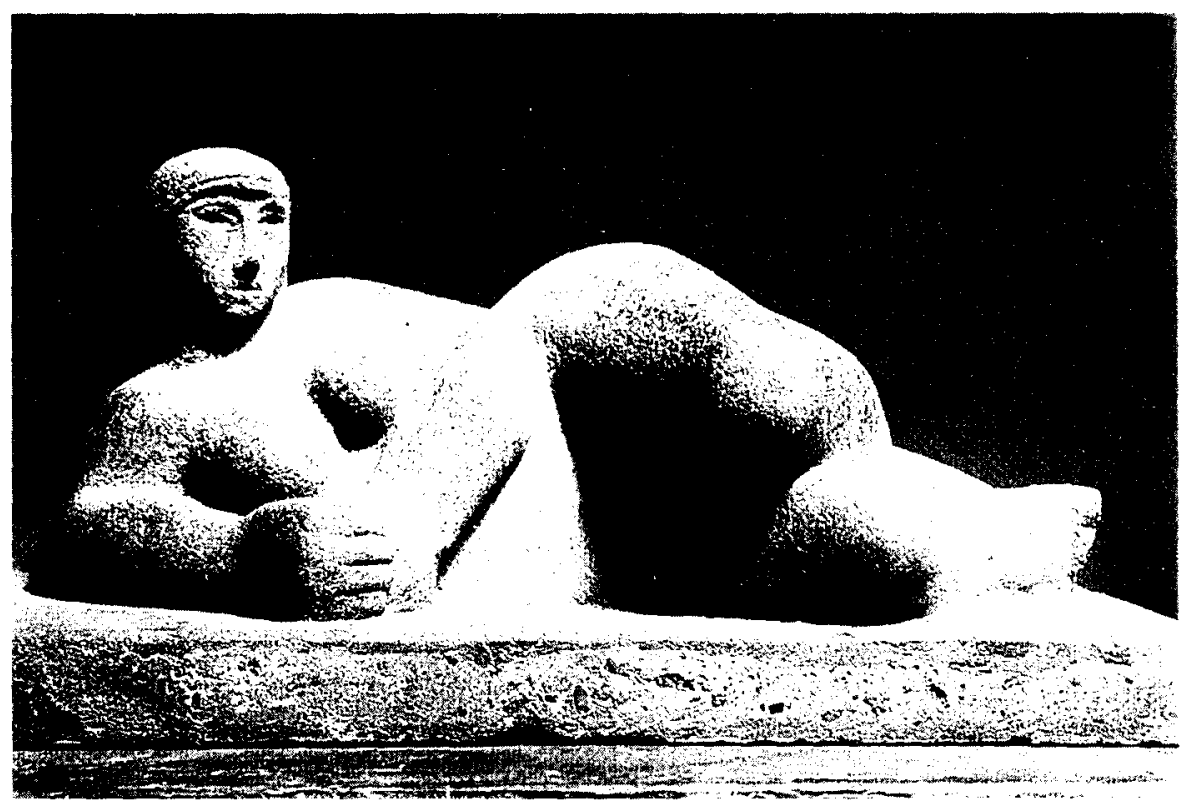

Fig. 5. Henry Moore: Mujer reclinada, 63,5 cm., 1927.

hormigón para realizar el volumen de una figura femenina recostada. Frente a la postura de pie o sentada, este tema le permitía una mayor libertad espacial y compositiva, por lo que se convirtió en uno de los favoritos de Moore, y de él haría diversas versiones. En ésta de 1927, la interpretación del cuerpo femenino responde todavía a una concepción claramente figurativa y no cercana a la abstracción. Su volumen compacto, cerrado y apretado, de una marcada monumentalidad, acentuada por la menor proporción de la cabeza, no se ve alterado por la plasticidad que genera en la obra de Moore el diálogo entre el espacio y la materia, ya que sólo es esta última la que origina una escultura de volúmenes firmes, rotundos y de perfiles marcados.

La investigación plástica llevó también a Picasso a realizar con grandes superficies de hormigón esculturas planas y monumentales - Mujer con los brazos abiertos (fig. 6) o Déjeuner sur l'herbe, esta última de 1965-, utilizando para ello un procedimiento que conoció gracias a su relación con el escultor Carl Nesjar (nacido en 1920). Esta técnica del "grabado de hormigón" había sido empleada por primera vez en Oslo por el arquitecto Erling Viksjö y el ingeniero Sverre Jystad, y consiste en grabar 


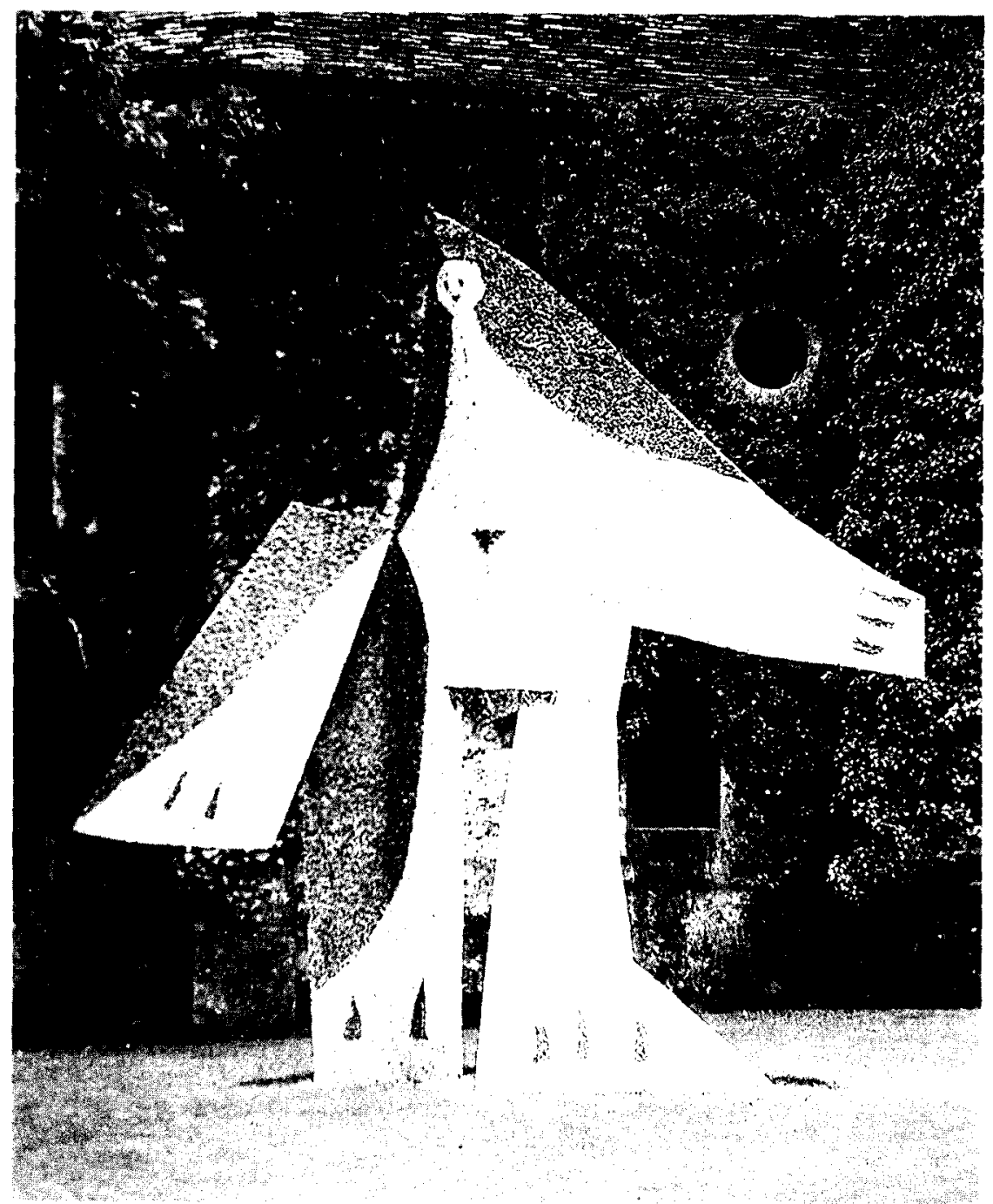

Fig. 6. Pablo Picasso y Carl Nesjar: Mujer con los brazos abiertos, $540 \times 500 \mathrm{~cm}, 1962$.

un dibujo sobre la superficie de hormigón con un soplete de chorro de arena ${ }^{9}$.

Spies, W.: La escultura de Picasso. Barcelona, Poligrafa, 1989, pág. 311. Véase también: FaIRWEATHER, S.: Picasso's concrete sculptures. New York, Hudson Hills Press, 1982. 
El origen del material plástico ${ }^{10}$ se remonta al siglo $x \mid x$, como resultado de la labor investigadora de Victor Regnault y Simon entre los años 1838 y 1839; más adelante, en la Exposición Internacional de 1862 se dio a conocer en Londres la "parquesina", un nitrato de celulosa descubierto por Alexander Parkes y D. Spill "1. En los años posteriores se fueron sucediendo determinados hallazgos químicos con los que se amplió considerablemente la variedad de una materia que también se ha ido introduciendo en el mundo del arte.

Cuando en el Manifiesto Realista de 1920 los hermanos Naum Gabo (1890-1977) y Antonio Pevsner (1884-1962) consideraron al «espacio como un elemento nuevo y absolutamente escultórico, como una sustancia material (...), uno de los principales atributos de la escultura", no sólo transformaron al vacío en una materia escultórica, sino también incorporaron otros nuevos materiales. El plástico y el vidrio fueron utilizados para construir estructuras basadas en la transparencia de unos planos, generadores de ritmos cinéticos que se oponian al tradicional concepto de la escultura, basado en la estática solidez de la masa.

En la Columna (fig. 7), Naum Gabo - uno de los escultores que incorporó el movimiento como innovación plástica, lo cual generó el cinetismo- reinterpretó este elemento sustentante de la arquitectura clásica por medio de la utilización de unos nuevos recursos formales, materiales y técnicos. El espacio, como una materia más, se mezcla en esta obra con la madera, el metal, el vidrio y un material plástico, el perspex, para configurar una estructura en la que la transparencia de determinadas materias

Las resinas y los plásticos han aportado una amplia gama de materiales que se han ido ir.corporando al campo de la escultura. Una de las resinas mas empleadas por los artistas es la de poliéster, que es líquida, pero por medio de la reacción quimica producida por dos elementos que generalmente son nattanato de cobalto (acelerador) y peroxido de metiletilcetona (catalizador), se transforma en una sustancia gelatinosa que, paulatinamente, se va endureciendo hasta solidificarse. En escultura se emplea la resina para estratificados y la resina para vaciados transparentes a las que se puede añadir pigmentos que le dan una determinada textura o color, permitiendo un acabado de bronce, piedra o mármol, etc.

Algunos escultores utilizan el poliéster como material detinitivo. mientras que otros lo trabajan como material auxiliar, concretamente en una de las fases intermedias de las grandes esculturas. es decir, como medio para obtener los positivos sobre los moldes de escayola sirviendo de muestra de lo que será posteriormente la obra. Tiene el inconveniente de ser quebradizo, de agrietarse en el exterior, por lo que es más recomendable para interiores y en obras de tamaño reducido. Sin embargo, para darle una mayor consistencia se le introduce una manta de fibra de vidrio empapada en poliéster hasta que todo fragua.

Véase: Mincley. B. (coord.): Guia completa de escultura, modelado y cerámica. Técnicas $\checkmark$ materiales. Madrid, Hermann Blume, 1982, pág. 168; Le Nohmand-Romain. A. el alii: La escultura. La aventura de la escultura moderna en los siglos xix y xx. Barcelona. Carroggio, 1986. pág. 236. 


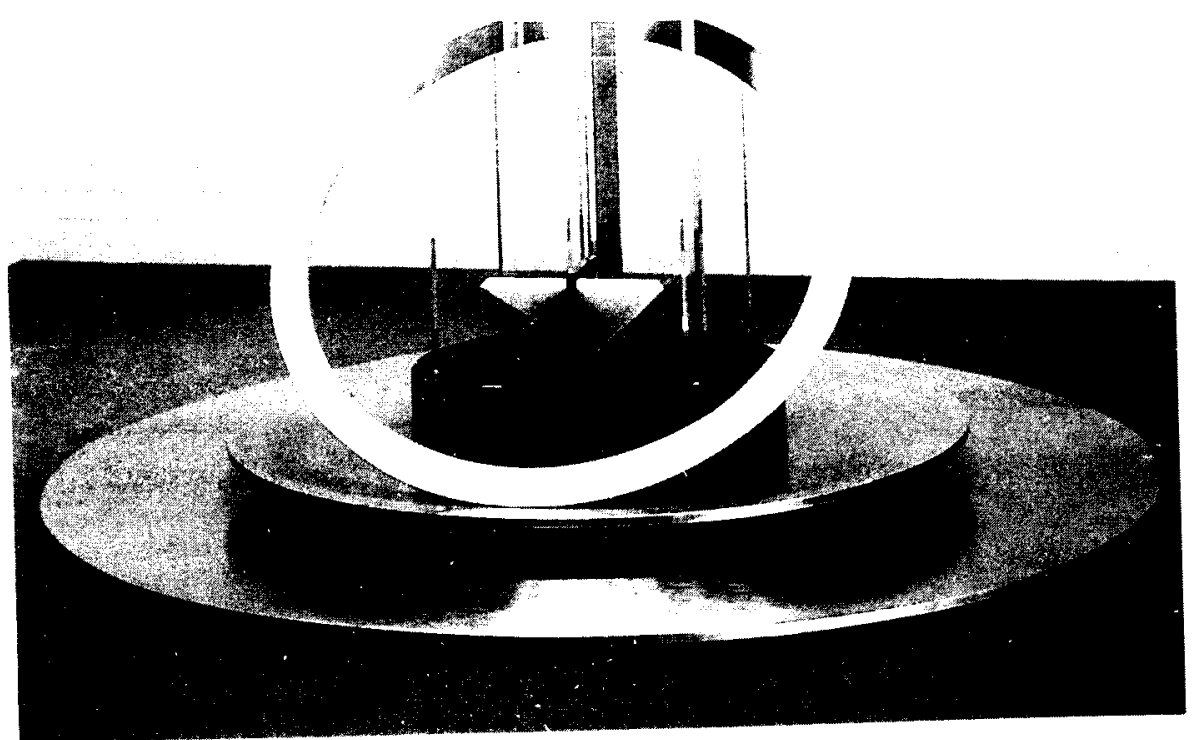

Fig. 7. Naum Gabo: Columna, $104 \mathrm{~cm}, 1923$. 
y la opacidad de otras definen la existencia de espacios interiores delimitados por el juego geométrico de los planos.

El plástico, por lo tanto, se revela como un material que contiene un gran potencial escultórico. Esta cualidad, puesta de relieve por los constructivistas rusos, también será aprovechada por uno de sus seguidores más destacados, el húngaro Laszlo Moholy-Nagy (1895-1946). Sus expresivas y dinámicas esculturas de plexiglás, realizadas en torno a 1940, ponen de relieve la articulación rítmica de lo curvo en el espacio por medio de la transparencia de un material que hace posible la incorporación a la obra de su entorno y de la luz que en ella se refleja.

A mediados del siglo xx, la utilización del plástico se acentúa. El poliéster será frecuentemente empleado en escultura, un material que Jean Dubuffet (1901-1985) incorpora a su obra a partir de 1966. El chismoso II (fig. 8) se caracteriza por una monumentalidad que acentúa el carácter grotesco de un personaje sentado sobre un sillón, y cuya actitud y expresivos gestos justifican el título por el que es conocida esta escultura. Los gruesos trazos y las manchas de pintura azul subrayan las conscientes deformaciones a la que Dubuffet ha sometido a la figura humana como expresión de su lenguaje artístico. Pero si en su obra el poliéster ha sido, entre otras, la materia utilizada para reducir al hombre a imágenes grotescas, escultores como Duane Hanson (nacido en 1925) y John De Andrea (nacido en 1941) también se han servido de él para "congelar" por medio de la técnica del vaciado momentos de la vida cotidiana, en los que los seres humanos son representados con un extraordinario verismo. acentuado éste por la policromía del material.

Además del cemento y de los plásticos, la práctica de la escultura en el siglo $x \times$ ha conducido también a la utilización de determinados metales ${ }^{12}$.

En la actualidad, además del bronce, tradicional en la escultura, se vienen empleando otros metales que desempeñan un papel muy importante en el conjunto de los nuevos materiales, destacándose entre ellos el hierro y el acero. El primero, de color gris, tiene una densidad de 7.85 , funde hacia $1530^{\circ} \mathrm{C}$ y hierve por encima de $3.200^{\circ} \mathrm{C}$. El acero es una combinacion de hierro y carbono, este último en una proporcion que va del 0.2 al $1,5 \%$; si es inoxidable lleva también níquel. En el tratamiento de los metales, una de las técnicas empleadas es la de la construcción surgida también de la renovación artística que se ha producido en el siglo xx como consecuencia de los adelantos en el campo científico e industrial. Esta nueva técnica permite emplear en una misma obra materiales tradicionales junto a los que han surgido recientemente, puesto que el resultado de este proceso es una obra integrada por un conjunto de elementos de diferente origen. De ahi las posibilidades que se le ofrecen al escultor en cuanto a la elección de materiales se refiere, al modo de ser distribuidos en dicha obra y al valor que en la misma se le puede dar a cada uno de ellos. En la construccion se emplea el metal. pero en ella se prescinde del vaciado es. cultorico por utilizarse métodos que son prcpios del proceso industrial, como puede ser el de la soldadura. 


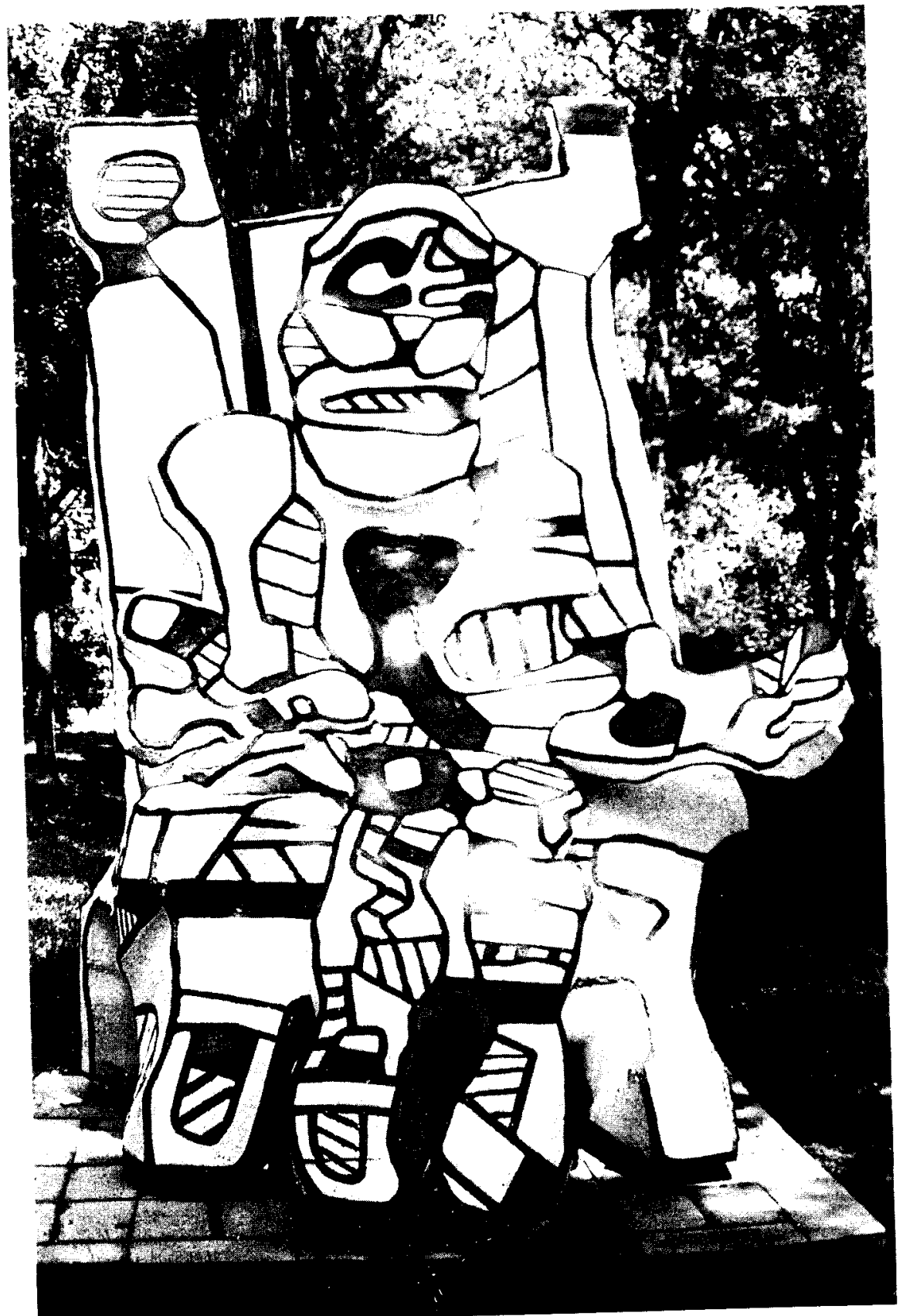

Fig. 8. Jean Dubuffet: El chismoso II, $304,8 \times 207,7 \times 216,5 \mathrm{~cm} ., 1984$. 
Uno de ellos, el hierro, ocupa un lugar muy destacado en el arte contemporáneo. Maleable, dúctil y al mismo tiempo tenaz, ha afirmado rotundamente su presencia en el terreno escultórico, y aunque partiendo de una fértil tradición, ha renovado radicalmente el mundo de las formas, que ocupan el espacio para desarrollar en él un sinfín de posibilidades combinatorias. Dicho metal, procedente del mundo industrial, ha pasado a formar parte de los nuevos materiales, pero su novedad es relativa, puesto que, como dice Gaya Nuño, es «más que nuevo (...) olvidado" ${ }^{13}$.

En la escultura contemporánea, el hierro está ligado al nombre de Julio González (1876-1942), quien trabajó directamente este metal por medio de la soldadura autógena -técnica aprendida por este escultor en 1918 al trabajar como aprendiz soldador en la compañía "La Soldadura Autógena Francesa" ${ }^{14}$ - para convertirlo en uno de los materiales más significativos del panorama artístico actual. Su colaboración con Picasso entre los años 1928 y 1931 fue muy provechosa para ambos. Refiriéndose a dicha colaboración, Werner Spies señala que "la aportación de González se limita de manera inequívoca a la ejecución práctica y al asesoramiento técnico. No hay influencia estilistica de González en Picasso. Éste admiraba la destreza técnica de aquél (...). El propio González no cayó en la cuenta de las nuevas posibilidades artísticas hasta que se puso a trabajar con $\mathrm{Pi}$ casso. Entonces fue cuando empezó a crear esculturas de metal similares. Como Picasso nos confesó, González le pidió permiso para trabajar de esta maneras 15 .

Consecuencia de dicha colaboración es la obra de Picasso titulada Mujer en el iardín (fig. 9), concebida en un principio como monumento a Apollinaire, aunque finalmente la conservó para él. Esta obra, pintada posteriormente de blanco, es una construcción que está integrada por planchas y varillas de hierro que se articulan en el espacio según un planteamiento muy esquemático. El cuerpo femenino y su entorno han sufrido una metamorfosis, y sólo son identificables por determinadas alusiones formales, tales como la cabeza con el cabello agitado por el viento junto a unas ramas de filodendro. Picasso no buscó en ella la perfección técnica, sino la espontaneidad, por lo que fue improvisando en su proceso de realización, en el que empleó diferentes técnicas: ensamblajes atornillados.

Gava Ninio. J. A. El hrerro en el arte espanol. Formas de la escultura contemporanea. Madrid. E. Aguado. 1966. pàg. 13

Datos recogidos por Al ix. J en el catalogo de la Escultura espaniola 1900-1936. Madrid. Ministerio de Cultura. Direccion General de Bellas Artes y Archivos. 1985. pag. 128

Sill $\therefore$ W. Op. cif. págs. 105 y 114 

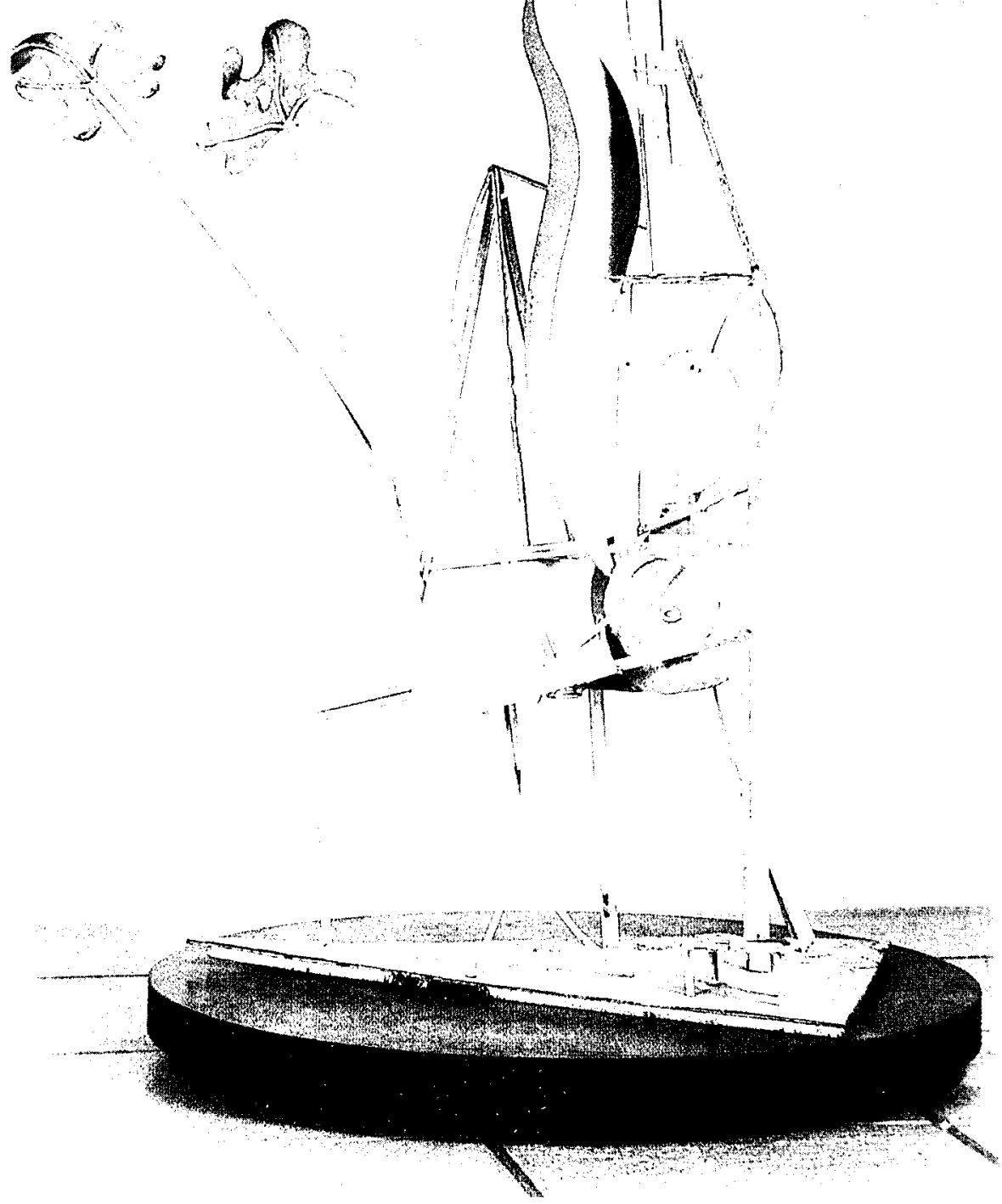

Fig 9. Pablo Picasso: Mujer en el jardin. $206 \times 117 \times 85 \mathrm{~cm} .1929$. 
soldadura y hierro repujado. Julio González, con el consentimiento de Picasso, realizó una réplica en bronce de esta pieza ${ }^{16}$.

La obra de Julio González, considerado por el escultor americano David Smith "el padre de toda la escultura en hierro de este siglo" "17, está basada en su personal interpretación del hombre y de la naturaleza. Lo esencial de su renovador estilo supone la búsqueda de nuevas soluciones formales que le llevaría a "dibujar en el espacio", a la unión de éste y la materia, a la fusión de "las formas reales con las imaginadas y sugeridas por los puntos establecidos, o bien, por perforaciones" ${ }^{18}$. En Mujer ante el espejo (fig 10), la instantaneidad de este momento ha sido captada por medio de unos elementos muy simplificados que sugieren la cabeza, inclinada hacia atrás, con unas varillas orientadas en la misma dirección, y que representan el cabello, mientras que la curva del brazo termina en una forma circular que envuelve al vacío para simbolizar el espejo. La acentuación del volumen en la parte inferior de la figura, con el predominio de lo cóncavo y de lo convexo, insinúan las caderas y los muslos. Esta consciente deformación del cuerpo femenino se ha traducido en la construcción de una estructura vertical que cobra nueva vida por el cauce de la abstracción figurativa.

La unión constructiva de elementos metálicos diferentes, integrados en el espacio, se aleja, por lo tanto, del concepto tradicional de la escultura, basado en la solidez de la masa, para introducirnos en un campo escultórico nuevo. El escultor, al igual que el ingeniero, construye estructuras de hierro en las que valora la naturaleza de este material a través de unas soluciones vinculadas a la estética industrial.

Junto a los nombres de Picasso y de Julio González podrían citarse el de otros escultores españoles que, al igual que los anteriores, también han contribuido notablemente a destacar el protagonismo del hierro dentro del arte contemporáneo. «No puede asegurarse - señala Juan Eduardo Cirlot- que toda escultura en hierro sea una creación estrictamente hispánica; pero lo cierto es que las obras sobresalientes ejecutadas en este material se deben a maestros españoles» ${ }^{19}$.

Al igual que el hierro, el vidrio es una materia utilizada por el hombre desde la antigüedad, pero ha sido en el siglo xx cuando se le ha dado un

lbidem, pág. 117

Julio González. Catalogue raisonne. Sculpture. Milano, Electa, 1987, pág. 9.

Gonzalez, R. Joan González. Juiio González. Robert González. Madrid. Publicaciones Españolas, 1968, tol. 17, rev.

Cirtot, J. E.: Arte del siglo xx. Arquitectura y escultura. Barcelona, Labor, 197Z, pág. 138. 


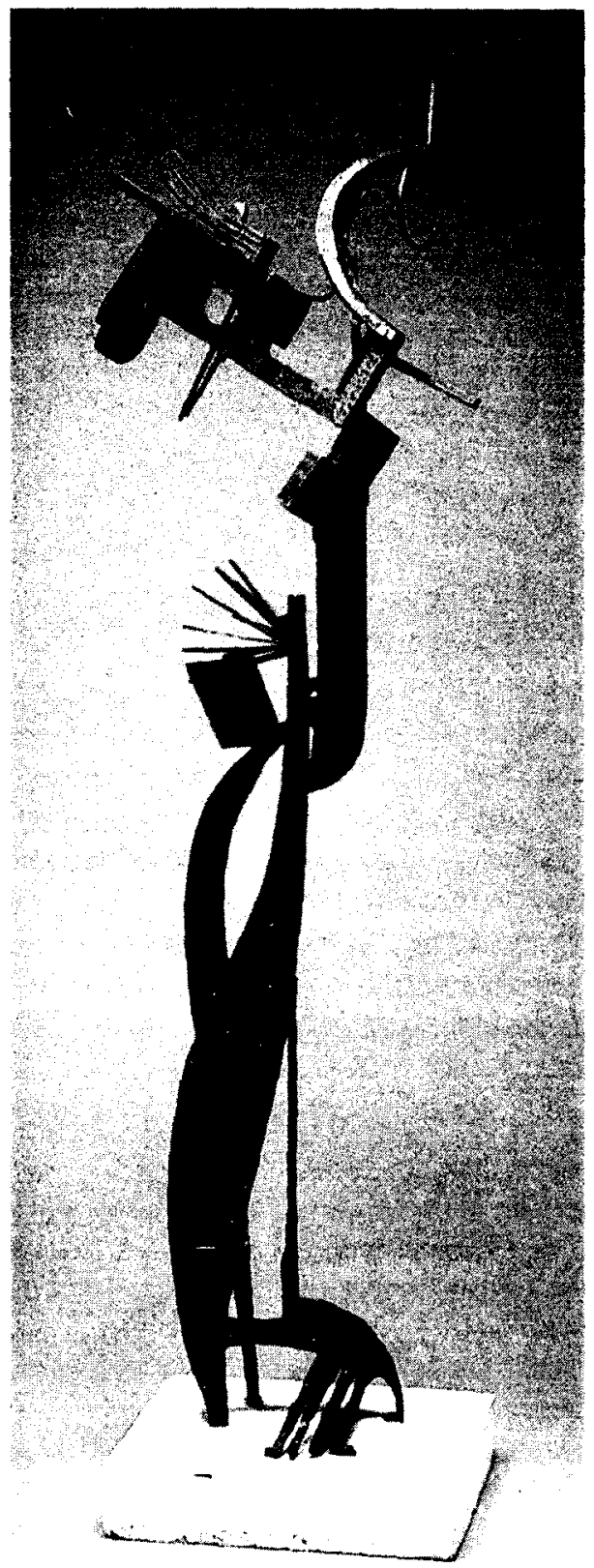

Fig. 10. Julio González: Mujer ante el espejo, 199,4 × 53.3 × 58,4 cm., 1936-1937. 
valor escultórico. Baste recordar el empleo que ya hicieron de él los constructivistas rusos al combinarlo con el plástico, el metal, la madera u otros materiales, con la intención de construir estructuras integradas en el espacio, y que rompían con la solidez del volumen monolítico de la escultura tradicional.

A mediados de este siglo el vidrio cobró una dimensión plenamente escultórica, capaz de generar formas orgánicas o geométricas, y en las que la incidencia de la luz posibilita un enriquecimiento insospechado de esta materia. No son pocos los artistas en el mundo que han sabido apreciar su dimensión escultórica, tampoco en España, aunque en nuestro pais se aprecia un retraso con respecto a los otros en esta práctica escultórica.

El vidrio laminado, un material de procedencia industrial, puede ser transformado en esculturas ${ }^{20}$ que responden a una organización formal capaz de originar perspectivas múltiples y cambiantes. Joaquín Torres Esteban (1919-1988) es el pionero de la escultura en vidrio laminado en España, un material también empleado en nuestro país por otros escultores como medio de expresión artística ${ }^{21}$. Uno de ellos, Javier Gómez (nacido en 1957), ha sabido arrancar al vidrio laminado sus posibilidades plásticas. En Libre en el espacio XVIII (fig. 11), la materia, que pugna por alejarse de la tierra, se combina con la luz y el vacio para originar unas formas dinámicas, de ritmos curvos, y también cambiantes por la variedad de puntos de vista existentes. La transparencia del material, de una tonalidad verdosa, es aiterada por la presencia de una variedad de juegos ópticos en función de la luz que la materia deja pasar. En las manos de Javier Gómez, el vidrio industrial abandona su rigidez para ganar espacialidad y dinamismo con la torsión de los elementos constitutivos de su escultura, un planteamiento formal que provoca la aparente disminución de su peso, a la vez que se evita la sensación de masa.

Una escultura de vidrio laminado se realiza a través de dos fases: el corte y el laminado. La primera de ellas se inicia partiendo de un boceto para proceder al corte de las láminas, que seguidamente serán pulidas. El laminado es una técnica cuyo adecuado conocimiento es impres. cindible para conseguir un buen acabado. Consiste en la unión de las laminas mediante pegamentos especiales. que serán secados con luz ultravioleta. Existen otras técnicas que sin ser imprescindibles para la ejecucion de una pieza, si pueden arrancar a la materia determinados efectos plásticos. Algunas de ellas son la del chorro de arena, que erosiona al vidrio para provocar en él alteraciones caprichosas; la utilización de esmaltes, para lograr efectos cromáticos: y eí craquelado, que supone controlar el intencionado resquebrajamiento de la materia.

Véase: Gonzal. 7 VICARIO, M. T.: “Un material clásico para una renovacion escultórica”, en Los Clasicismos en el Arte Español (Madrid. Departamento de Historia del Arte. U.N.E.D., 1994). págs. 165-171. 


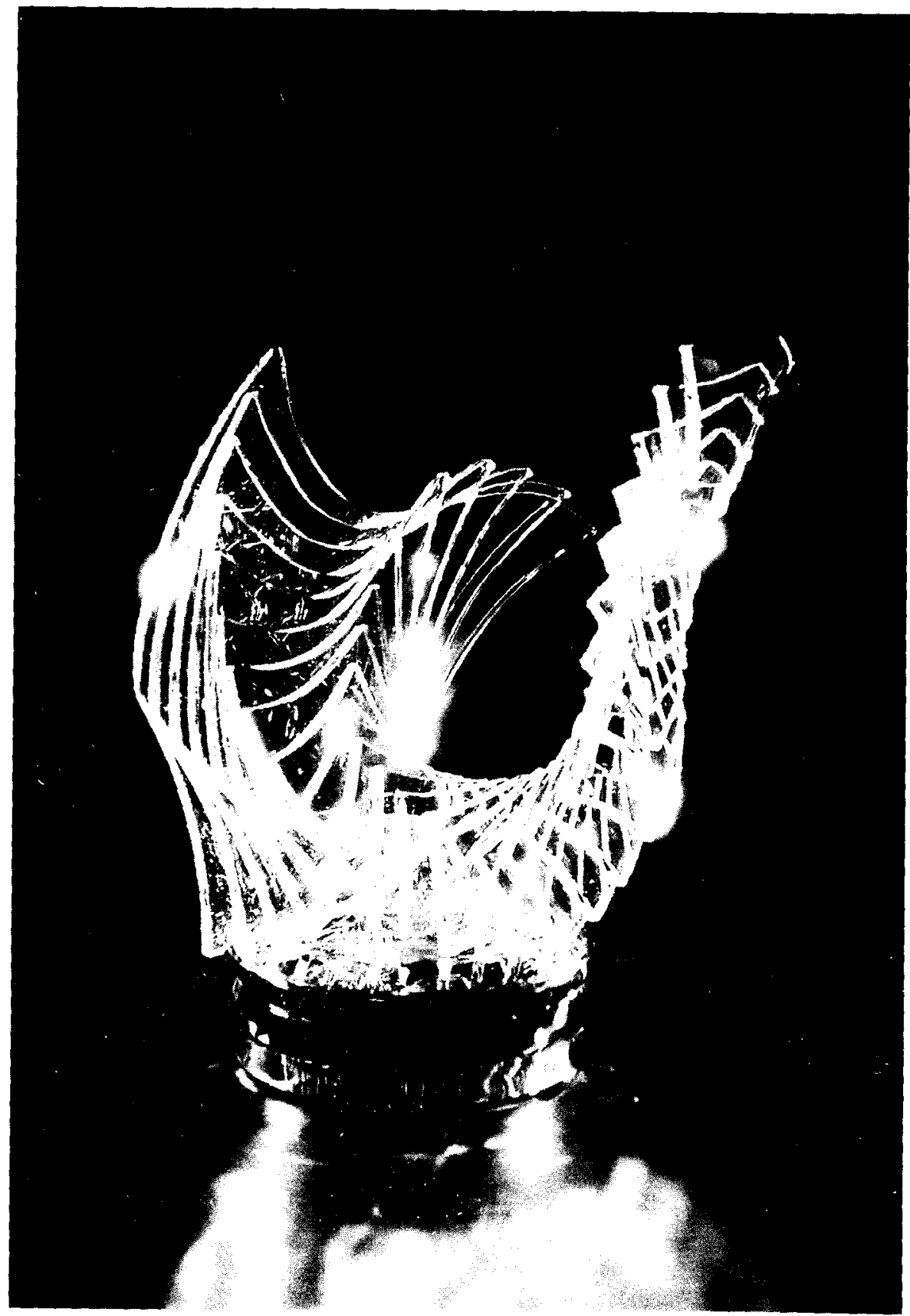

Fig. 11. Javier Gómez: Libre en el espacio XVIII, $27 \times 26,6 \times 17 \mathrm{~cm}$., 1996. 
Además de estos materiales y técnicas nuevos, existen otros que son también innovadores, pero la referencia a la totalidad de los mismos excedería los límites de este trabajo. Por otra parte, la utilización de todos ellos no comporta que el escultor contemporáneo haya abandonado la práctica de los materiales y técnicas tradicionales, sino que, por el contrario, éstos también son valorados como medio de expresión plástica en el siglo $x X$.

Constantin Brancusi (1876-1957) y Henry Moore, dos escultores cuyo proceso creativo se ha caracterizado por una clara voluntad de ruptura con respecto a los valores escultóricos tradicionales, emplearon, sin embargo, materiales y técnicas convencionales, pues el empleo de un nuevo material no es garantía de modernidad ni el uso de uno convencional supone una afirmación de tradicionalismo. El bronce, el mármol o la madera permitieron a Brancusi la realización de unas creaciones plásticas, basadas en volúmenes esenciales, muy depurados, que le fueron sugeridos por las formas orgánicas de la naturaleza. En opinión de Herbert Read, su evolución está marcada por «dos ideales apremiantes: la armonía universal y la veracidad en el trato de los materiales" "22. En el Comienzo del mundo (fig. 12), obra que por su concepción formal y también por el tratamiento técnico del mármol constituye un claro exponente del estilo de este escultor, Brancusi ha valorado la plasticidad de una materia de pulidas superficies a través de un volumen ovoide, hermético, sólido y perfecto. Según Hans Joachim Albrecht, en esta obra «ninguna interrupción abre la absoluta totalidad cerrada del ovoide puro. Parte de una zona central y se extiende en todos los sentidos, empujando un impulso intenso exclusivamente hacia los dos polos. Se puede conocer la esencia de lo plástico en la integridad y en la naturaleza compacta de esta masa en expansión, que llena de un extremo a otro el espacio ampliado por ella» ${ }^{23}$.

Por el contrario, la búsqueda escultórica de Henry Moore se tradujo en una equilibrada y rítmica articulación del lleno y del vacio, a través de la valoración plástica de la materia y del espacio, sin que en su actividad artística los materiales tradicionales, tales como el bronce, el mármol y la madera, fueran ajenos a la misma. La ductilidad y calidez de esta última materia, ya valorada desde los primitivos, se ciñe también a la práctica artística del escultor contemporáneo. En Figura reclinada (fig. 13), la madera de olmo fue el material elegido por Moore para configurar uno de sus

READ, H.: La escultura moderna. Barcelona, Destino, 1994, pág. 80.

Al BRFCHT. H. J.: Escultura en el siglo XX. Conciencia del espacio y configuración artistica. Barcelona, Blume, 1981, págs. 120 y 121 


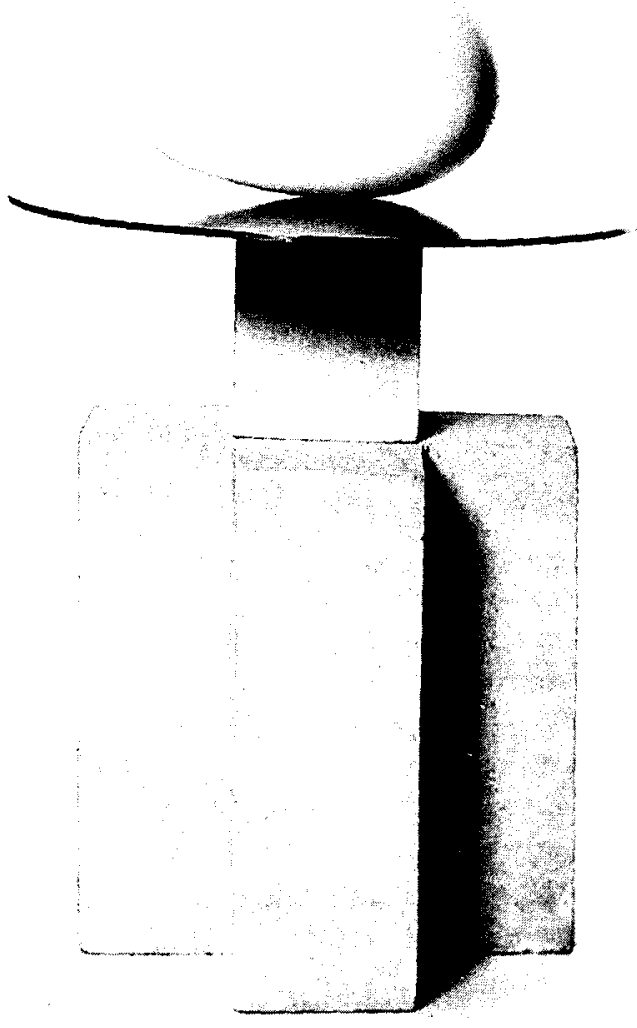

Fig. 12. Constantin Brancusi: El comienzo del mundo, $17 \times 30,5 \times 23 \mathrm{~cm}$., 1924 . 


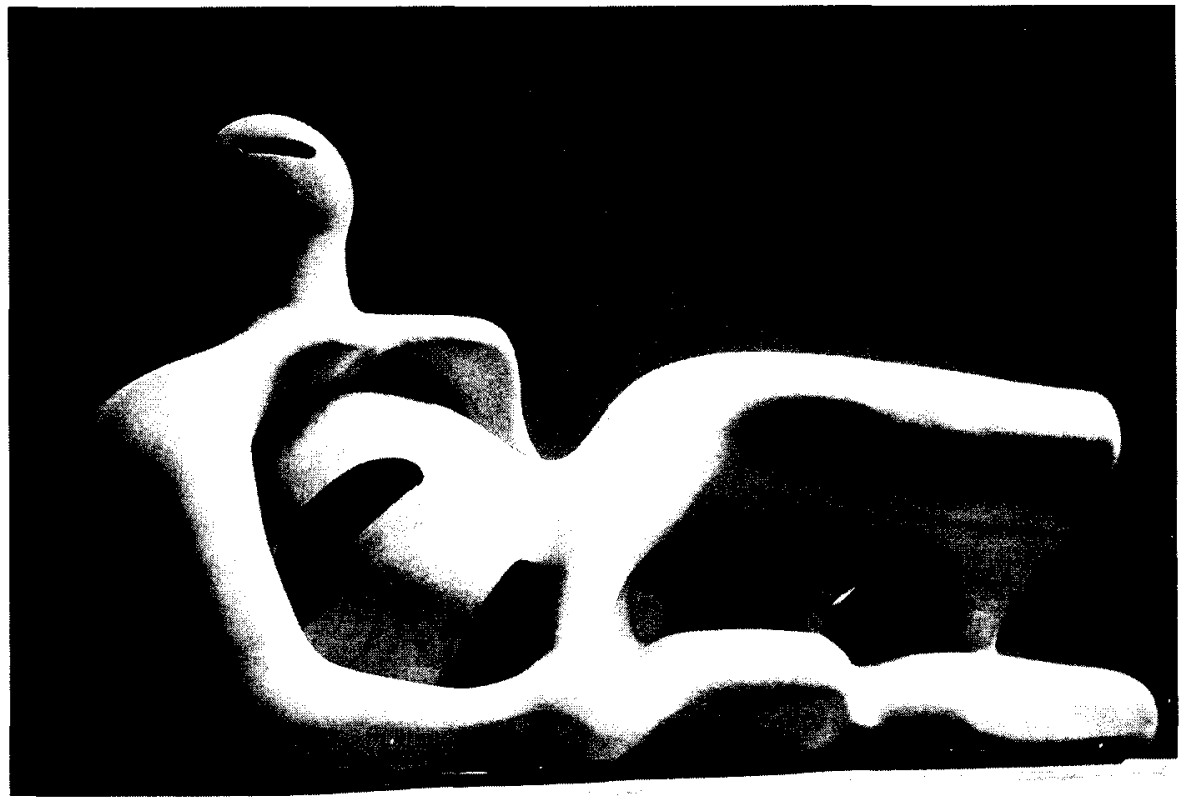

Fig. 13. Henry Moore: Figura reclinada, $190 \mathrm{~cm}$., 1945-1946.

temas predilectos, como ya se dijo anteriormente (fig. 5). Sin embargo, esta última versión ha sido concebida con una clara voluntad abstracta, a la vez que en ella ya se hace presente el dinámico juego de lo hueco y de lo sólido. Su volumen horadado presenta una multiplicidad de puntos de vista, de perspectivas, que destacan el tratamiento escultórico del espacio y la plena plasticidad de sus perfiles sinuosos, que parecen evocar colinas, rocas, grutas o valles, es decir, formas inspiradas en la naturaleza.

Todas estas modificaciones, entre otras, que la práctica artística del escultor contemporáneo ha ido experimentando a lo largo del siglo xx, se han traducido en el desarrollo de nuevos materiales y técnicas, junto a los ya tradicionales, que han originado su propio lenguaje formal y unos comportamientos de trabajo radicalmente nuevos. La escultura actual, por lo tanto, responde a una nueva estética que también requiere una nueva forma de ver, de valorar y de desarrollar el trabajo del escultor. Cualquier materia, por infima que ésta sea - baste recordar las obras que pertenecen al arte "povera"-, puede convertirse en un medio de expresión artística, sin que en determinadas manifestaciones se advierta la preocupación por su permanencia, dado ei carácter efímero de las mismas. Por el contrario, en otras ocasiones, y también como consecuencia de la utiliza- 
ción de materiales y técnicas industriales, la escultura reafirma su presencia al abandonar sus límites habituales en el espacio, para ocuparlo con unas dimensiones que la hacen equiparable a la arquitectura. En consecuencia, el valor que tradicionalmente se venía dando al pedestal, a la base de la escultura, pierde su tradicional significado ${ }^{24}$.

Estas consideraciones, junto a otras que podrian hacerse, ilustran la ruptura que se ha operado en el siglo $x x$ con respecto a los anteriores procesos creativos de la escultura, una ruptura que ha sido propiciada por el progreso científico y tecnológico, en el que la máquina ha ejercido un marcado protagonismo para modificar la vida del hombre y transformar también su actividad artística. La práctica del escultor contemporáneo responde, por lo tanto, a una nueva sensibilidad que ha generado unas convicciones estéticas radicalmente innovadoras y son, además, expresión de la diversidad plástica del siglo xx, dominada por el protagonismo de la materia.

24 Sobre la convergencia que en el siglo $x \times$ se da entre la escultura y la arquitectura, véase: Maderuelo, J.: El espacio raptado. Madrid, Mondadori, 1990; este mismo autor analiza la transformacion sufrida por los conceptos de escultura y monumento en: La pérdida del pedestal. Madrid, Círculo de Bellas Artes, Visor Dis., 1994. 
